\title{
Impact of HR Practices on Employee Retention in Oil and Gas Industries of Oman
}

\section{Ahmed Humaid Al Habsi, Nadia Farhana, Asif Mahbub Karim}

To Link this Article: http://dx.doi.org/10.6007/IJARBSS/v11-i9/10847

DOI:10.6007/IJARBSS/v11-i9/10847

Received: 09 July 2021, Revised: 11 August 2021, Accepted: 30 August 2021

Published Online: 18 September 2021

In-Text Citation: (Habsi et al., 2021)

To Cite this Article: Habsi, A. H. Al, Farhana, N., \& Karim, A. M. (2021). Impact of HR Practices on Employee Retention in Oil and Gas Industries of Oman. International Journal of Academic Research in Business and Social Sciences, 11(9), 1520-1530.

\section{Copyright: (c) 2021 The Author(s)}

Published by Human Resource Management Academic Research Society (www.hrmars.com)

This article is published under the Creative Commons Attribution (CC BY 4.0) license. Anyone may reproduce, distribute, translate and create derivative works of this article (for both commercial and non-commercial purposes), subject to full attribution to the original publication and authors. The full terms of this license may be seen at: http://creativecommons.org/licences/by/4.0/legalcode

Vol. 11, No. 9, 2021, Pg. 1520 - 1530

Full Terms \& Conditions of access and use can be found at http://hrmars.com/index.php/pages/detail/publication-ethics 


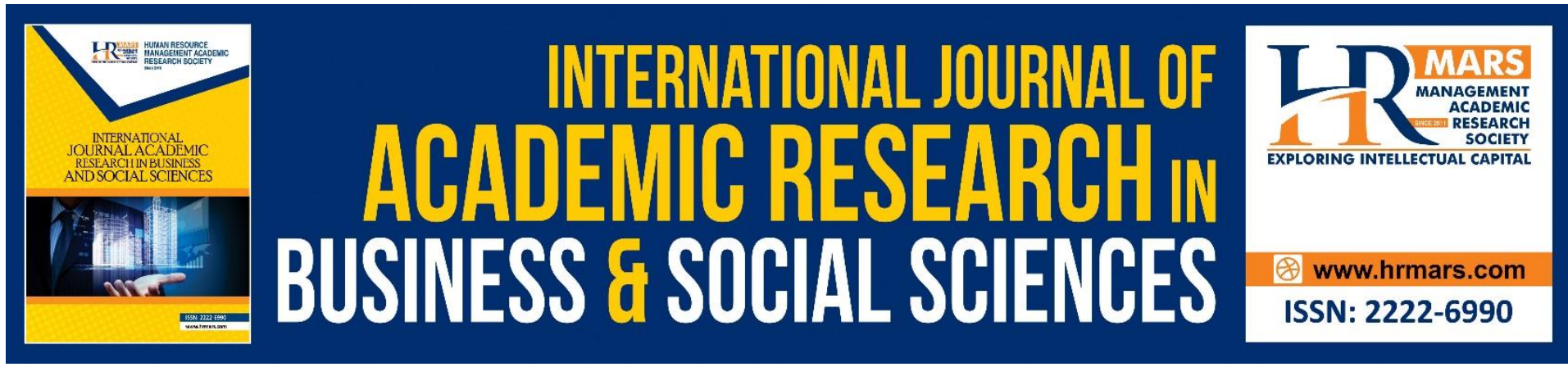

\title{
Impact of HR Practices on Employee Retention in Oil and Gas Industries of Oman
}

\author{
Ahmed Humaid Al Habsi \\ Binary University of Management and Entrepreneurship Selangor, Malaysia \\ Dr. Nadia Farhana \\ Stamford University Bangladesh Dhaka, Bangladesh \\ Dr. Asif Mahbub Karim \\ Binary University of Management and Entrepreneurship Selangor, Malaysia \\ Email: alalawi.ahmed.ali@gmail.com
}

\begin{abstract}
Effective human resource management fosters workplace loyalty and boosts an organization's productivity to new heights. Gulf nations, especially Oman, have similar problems as other countries. A WTO treaty has been signed and developed, requiring Omani businesses to demonstrate their presence in global markets and compete internationally. Omani companies are left with few options. Either they adapt, or they die in today's fiercely competitive marketplace. Omani oil firms are being compelled to abandon their traditional work culture in favor of modern work environments. The primary aim of this study is to investigate the current practices of human resource management employed by oil and gas companies of Oman and assess how to retain human resources in Oman's oil and gas companies. It has been found that the majority of respondents in Oman's oil and gas sector endorse the company's human resource policies and the company's staff retention strategy. At the same time, according to Pearson Correlations Coefficient and Multiple Regression Analysis, an apparent positive connection can be seen within human resource strategies and employee retention in Oman's oil and gas sector.
\end{abstract}

Keywords: Human Resource Management, Employee Retention, Oil And Gas Industries, Productivity, Online Survey.

\section{Introduction}

Human Resource management is regarded as the approach that is taken by the management or organizations to improve the workplace environment of the employees and provide a competitive edge to the organizations so that productivity and profitability levels could be increased significantly (Hendry \& Pettigrew, 1986). The Human resource management is done by a selected group of people who form a Human Resource Department and carry out their practices and functionary through it. The implementation of effective HR practices leads to the establishment of workplace loyalty and increases the productivity of the organizations to 
high levels. The Gulf region is found to be developing at a fast pace. As per the data released by the Gulf Cooperation Council (GCC), it was found that the nominal growth in Gulf countries had been recorded as about $20 \%$ per year. The region is known for producing and exporting oil and gas to the rest of the world. The region is growing exceptionally with growth in direct investments up to 2 billion in 2001 which increased to more than 20 billion in 2005 . The major strength of the population that is about $40 \%$ estimated to be about 38.5 million population is found to be under the age of 15 years (Farouk et al., 2016).

Effective human resource management (HRM) techniques have long been recognized as critical for eliciting good work behaviors among workers, which ultimately leads to effective invention (Tan \& Nasurdin, 2010; Damanpour \& Gopalakrishnan, 1998). According to Harter et al. (2002), human resource management techniques may result in improved organizational learning, enthusiasm, synergy, and dedication, providing the company with a source of sustainable competitive advantage. Several researchers, including Moynihan et al (2001); Morrow and McElroy (2001); Hilsop (2003) stated that a disconnect exists between human resource management methods and organizational results.

The Gulf countries like Oman have been characterized as the regions where the presence of expatriate workers could be found in large proportions. Although the unemployment rate is found to be low in the region the workers are found to be mostly working under short-term contracts which are renewed as per the needs and requirement of the oil companies. In many of the oil companies, no presence of the Human resource department could be seen. There is no provision of any incentive towards the incorporation of HRM or practices. Many organizations in the Gulf region consider that investment done by them in the implementation of HRM practices is not fruitful and unnecessary (Cross et al., 2004). However, it is observed that due to globalization the oil companies in these regions are facing a lot of challenges to compete in the global markets. Off late, the oil companies in Gulf are realizing the importance of Human resource strategies and its relevance to the operations of their businesses. Several types of research and studies have been done in the field of Human Resource practices related to work behavior, organizational commitment, and labor productivity. Many scholars and researchers have carried out such studies in North America, and the UK. The researchers have also taken the countries like Greece, Singapore, Taiwan, India, Japan, New Zealand, and Korea into consideration and tried to provide details and proceedings carried out by Human Resource practices in these countries (Chhabra \& Mohanty, 2014).

In the competitive business environment, it has become essential to outline the role of the different functionaries of the department including the Human Resource roles and responsibilities so that the organizations could work in a proficient manner (Brynjolfsson \& Hitt, 2000). The Human Resource personnel develop extensive training courses and workshops, seminars, motivational programs, etc. so that the working force could perform in a better manner. Human Resource practices refer to the practices proposed through the medium of HR systems which lay high implications for the employees and the organization. To provide a better vision of the Human Resource practices many books and article had been written by various intellectuals since the 1980s which were published by American Business Schools Professors. The Human Resource practices are found to be different in various countries depending upon the culture and customs of the nations and availability of human resources. The HR practices highly differ among organizations based on individual behavior, educational background, social construction, organizational psychology adopted, market relations, organizational structure, and theory. The Human Resource practice brings positive 
changes to the working attitude and behavior of the employees (Bloom \& Van Reenen, 2010). The HR managers lay stress on increasing employee participation in the organization by providing them with training, encouraging teamwork participation, mentoring, promoting, rewarding, etc. All of these variables have a beneficial effect on employees. Due to the positive work environment and high levels of motivation, the employees are provided with better working conditions the performance levels of the employees get increased. The HR managers also found to be addressing the employee concerns and grievances in a proper manner. They provide competitive salaries, compensation, incentives, etc. to the employees. This gives workers with a feeling of security and loyalty to the company. The employees are found to be satisfied and remain committed to the organization increasing the employee loyalty towards the organizations (Belwal \& Belwal, 2014). This highly impacts the organizational commitment and labor productivity level of the organizations. The researcher paper effectively covers the different aspects of the influence of HR strategies on organizational commitment and labor productivity in oil companies of Oman. The HR practices are responsible for bringing positivity into working conditions of the oil companies in Oman due to which the employee productivity and loyalty get influence in a positive manner. The different Human resource practices for enhancing work culture and behavior in oil companies of Oman is also included in the research study (Bashir et al., 2014).

In spite of so much growth, exploration and expansion going on in this region, very less research in the area of human resource management is found. Moreover, the Human Resource management strategies that exist in the oil companies in the Arabian Gulf countries like the Sultanate of Oman has never been studied or tested. In this research study, details about the Human Resource management strategies that are carried out in oil companies in Oman has been provided. The paper analyzed demographic information based on gender, age, education level, job tenure, and organizational position. Additionally, descriptive analysis of variables including HR practices and employee retention was also investigated. Simultaneously, some significant factors such as normality test, reliability, Pearson correlation coefficient, and multiple regression analysis were also explored. Hence, this research paper has the potential to fill the gap of human resource practices on employee retention in Oil and Gas Industries of Oman.

\section{Methodology}

The factor chosen as the recommended theoretical framework was human resource practices. It has a significant impact on employee retention. Management and higher-level workers of Oman's oil and gas firms were chosen as the population for this research. A structured questionnaire was used as the survey tool. The questionnaire was developed after thoroughly assessing the context of social media use and academic achievement. The questions chosen for the questionnaire were taken from related scientific studies. The questionnaire was developed with the possibility of probable variability. It contains several demographic questions about the responder. For the majority of the questions, 5-point Likert scales were utilized, which is an easy-to-use technique for responders to evaluate things.

\section{HR Practices Employee Retention}

Figure 1: Conceptual Framework 
The primary source of data collection was done by conducting face to face interviews and an online interview with the selected set of individuals. The interviewee was given a list of themes and questions and they were obliged to respond to all questions but were also allowed to bring about necessary changes to the question pattern as per the need of the response to be provided. Online surveys were conducted to collect the data in a fast and easy way as more people are accessible through the application of this medium. The questionnaire was set accordingly to the factors, which took approximately 3-5 minutes to complete. The questionnaire included a total of 12 questions, all of which were closed-ended. The questions were framed to show the type of users as per their gender, age, educational qualification, and profession.

Questionaries
\begin{tabular}{|l|l|}
\hline HR Practices & Employee Retention \\
\hline HP1. Company recruit on the basis of merit & ER1. Employees would hate to quit this job \\
\hline $\begin{array}{l}\text { HP2. Company practice Non-discriminatory } \\
\text { recruitment }\end{array}$ & $\begin{array}{l}\text { ER2. Employees plan to work in this } \\
\text { company for as long as possible }\end{array}$ \\
\hline $\begin{array}{l}\text { HP3. Company offers ongoing training that } \\
\text { enhances and secures workers' jobs }\end{array}$ & $\begin{array}{l}\text { ER3. One of the primary reasons workers } \\
\text { stay with the organization is that another } \\
\text { company may not be able to match the total } \\
\text { advantages gained. }\end{array}$ \\
\hline $\begin{array}{l}\text { HP4. Company treated employees equally } \\
\text { programs offer guidance to new workers, } \\
\text { which results in increased retention }\end{array}$ & $\begin{array}{l}\text { ER4. This company encourages staff to work } \\
\text { longer in the hotel }\end{array}$ \\
\hline $\begin{array}{l}\text { HP6. Organizations that adhere to a } \\
\text { consistent performance evaluation system } \\
\text { foster employee commitment to the } \\
\text { organization's development }\end{array}$ & $\begin{array}{l}\text { ER6. Staff redundancy takes place every year } \\
\text { in the company }\end{array}$ \\
\hline
\end{tabular}

\section{Results and Discussion \\ Demographic Information}

The demographic profile has been discussed based on gender, age, education level, job tenure, and organizational position and results on the demographic profile have been presented in Figure 2. The result demonstrated that $71.5 \%$ were male and $28 \%$ were female among the respondent, so most of the respondents were male. In the meantime, among the respondents, the $41-50$ years age group was the highest (36.4\%) while the 30 years or less were the lowest (1.8\%). Meanwhile, respondents who completed undergraduate education were the highest while trade education completed respondents were the lowest. The demographic profile also presented that 1 year or less job tenure was the highest among the respondents, while 4 years were the lowest. Moreover, in terms of organization position, the specialist was highest while the supervisor was lowest among the respondents. These demographic profile findings represented that the respondent's response was good to support the objectives of this study. 
INTERNATIONAL JOURNAL OF ACADEMIC RESEARCH IN BUSINESS AND SOCIAL SCIENCES Vol. 11, No. 9, 2021, E-ISSN: 2222-6990 @ 2021 HRMARS

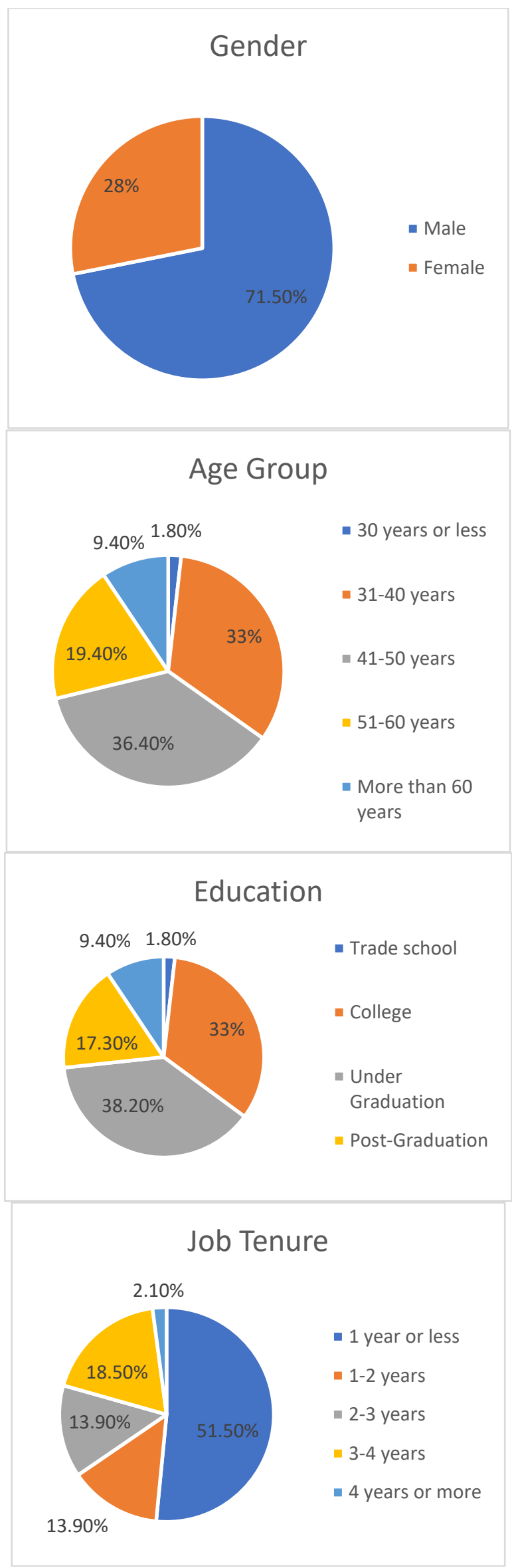




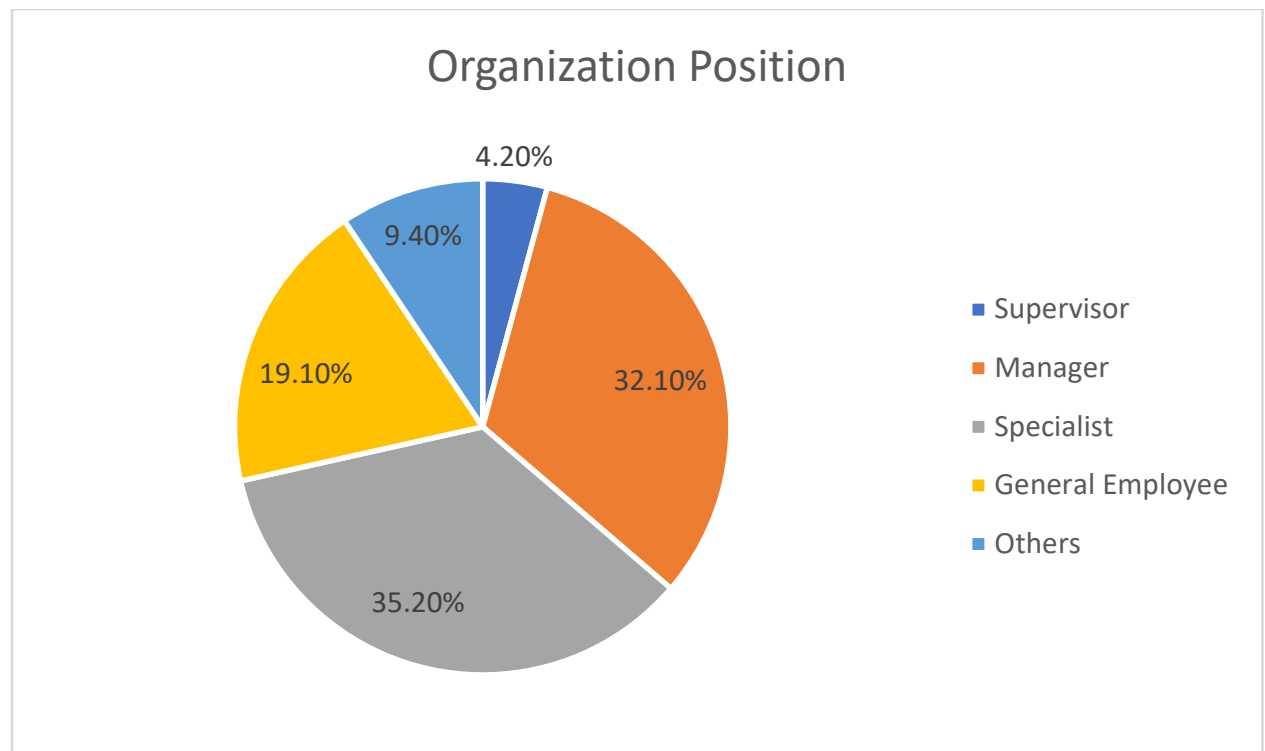

Figure 2: Demographic profile (a) gender, (b) age group, (c) education, (d) job tenure, (e) organization position

\section{Descriptive Analysis of Variables \\ HR Practices}

To evaluate the organization's HR practices (independent variable), six different questions were considered to receive responses from the respondent. The response from the survey was summarized in Figure 3. The results from Figure 3 demonstrated that among the respondents, most of them support the questions and provide positive responses. The majority of respondents strongly agreed that the company recruit on the basis of merit (HP1). Meanwhile, the highest number of respondents were not sure that the company practice nondiscriminatory recruitment, organizations that use a usual performance evaluation system foster employee confidence in the organization's growth and organizations that offer mentoring programs provide direction to new employees, resulting in employee retention. Moreover, the highest number of respondents agreed that the company treated employees equally and provides continuous additional training to improve and secure employees' jobs. The response of disagreed and strongly disagreed was lowest from the respondents on the $H R$ practices. Therefore, the findings reported that the employees positively support the HR practices of the company.

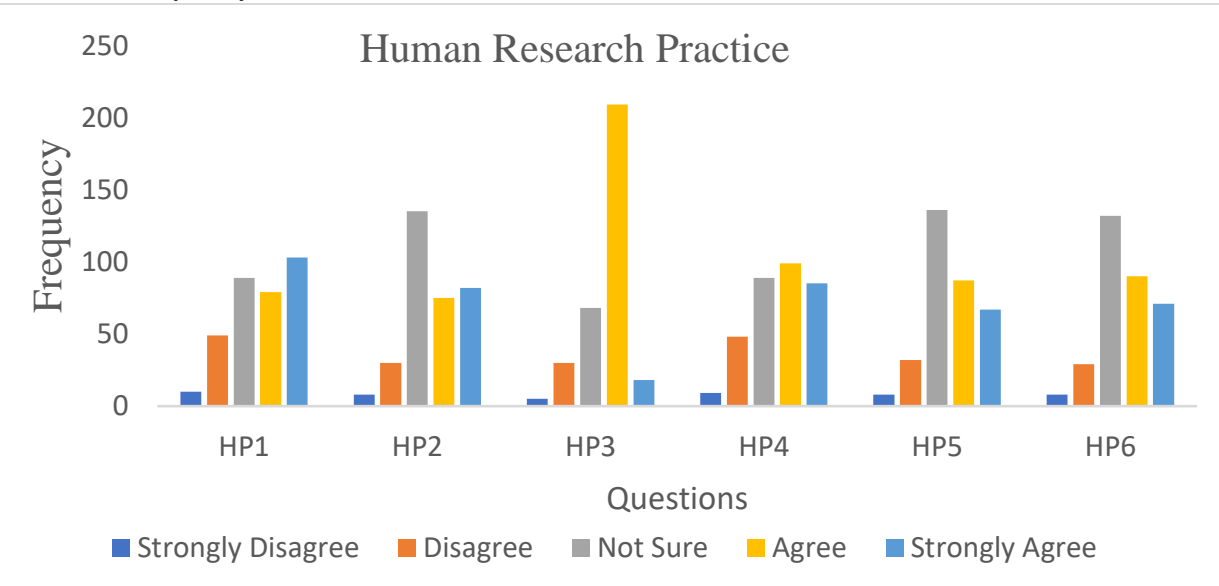

Figure 3: Human research practice according to response from the respondent 


\section{Employee Retention}

To evaluate the employee retention (dependent variable) in the organization six different questions were considered to receive responses from the respondent. The response from the survey was summarized in Figure 4. The results from Figure 4 demonstrated that among the respondents, most of them support the questions and provide positive responses. The highest number of respondents were agreed that employees plan to work in this company for as long as possible; one of the primary reasons people will stay with the company is that another company may not reach the entire privileges obtained, and this company encourages employees to stay longer. Meanwhile, the highest number of respondents were not sure that Employees would hate to quit this job, employees have no future obligations to this company, and staff redundancy takes place every year in the company. The response of disagreed and strongly disagreed was lowest from the respondents on employee loyalty. Therefore, the findings reported that the employees positively support the employee retention process to the company.

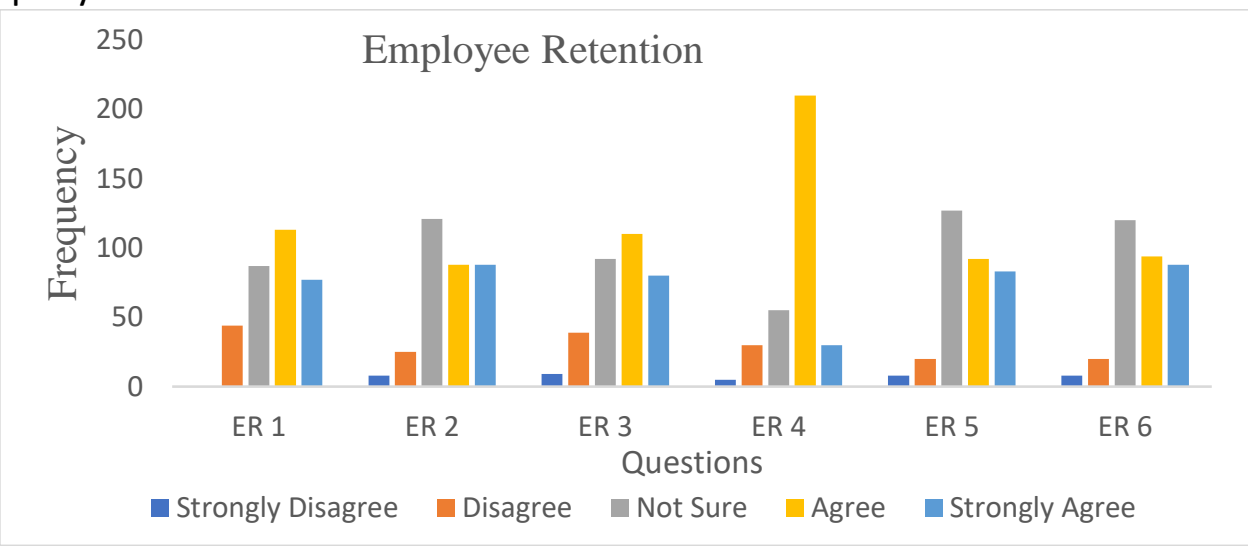

Figure 4: Employee retention according to response from the respondent

\section{Normality Test}

Table 2 summarizes the findings of two renowned normality tests, the "Shapiro-Wilk" and the "Kolmogorov-Smirnov". Shapiro-Wilk is a widely used normality test. However, it does not perform well when data is duplicated or sample sizes are large. The Kolmogorov-Smirnov test is used to evaluate Gaussian distributions with a specified mean and variance. The "ShapiroWilk Test" is more appropriate for small datasets (50 samples), but it is capable of handling sample sizes of up to 2000. As a consequence, the "Shapiro-Wilk test" was applied to establish numerical normality.

MEANHP and MEANER were regularly distributed, as shown in Table 2. When the sig. value exceeds 0.05 , the "Shapiro-Wilk test" shows that the variable is normal. If it is just under 0.05 , the results are significantly out of the usual range.

Table 2: Tests of Normality

\begin{tabular}{|l|l|l|l|l|l|l|}
\hline \multirow{2}{*}{} & \multicolumn{3}{|l|}{ Kolmogorov-Smirnov $^{\mathrm{a}}$} & \multicolumn{3}{l|}{ Shapiro-Wilk } \\
\cline { 2 - 7 } & Statistic & $\mathrm{df}$ & Sig. & Statistic & $\mathrm{df}$ & Sig. \\
\hline MEANHP & .159 & 330 & .000 & .927 & 330 & .000 \\
MEANER & .108 & 330 & .000 & .938 & 330 & .000 \\
\hline
\end{tabular}

a. "Lilliefors Significance Correction" 


\section{Reliability}

The "Cronbach's alpha value" is often utilized to assess a research project's degree of accuracy. The degree to which an activity is error-free and delivers consistent outcomes is referred to as reliability (Zikmund, 2003). The term "Cronbach's Alpha" refers to the degree to which the elements in a collection are related. Additionally, scales with "alpha coefficient" values within 0.8 to 0.95 have the highest amount of reliability, those with values within 0.7 to 0.79 have a moderate amount of reliability, those with values within 0.60 to 0.69 have a fair amount of reliability, and those with values less than 0.6 have the lowest amount of reliability.

Table 3: Reliability Statistics

\begin{tabular}{|l|l|l|}
\hline Cronbach's Alpha & Cronbach's Alpha Based on Standardized Items & N of Items \\
\hline .968 & .976 & 30 \\
\hline
\end{tabular}

Cronbach's alpha is higher than 0.70 for the majority of variables. As a result, the questionnaires used in this study were considered to be of high accuracy and stability.

\section{Pearson Correlations Coefficient}

This study is for the hypothetical connection between human resource practices and employee satisfaction. Pearson's $r$ is 0.958 in this case. This value is very near to one. This indicates that your two variables have a strong connection. This indicates that the values of one variable are highly linked with those in the second. As a consequence, it can be deduced that human resource strategies and employee happiness are positively correlated. However, based on this statistic, we cannot draw any further inferences regarding this connection.

Another method is to examine the Sig value. Whenever the 2-Tailed "Sig value" is below or equal to .05 , it can be inferred that these two variables' relationship is statistically meaningful. That is, changes in one variable have a substantial relationship with changes in the second variable. The sig value, in this case, is 0.000 , which is less than 0.05 . Thus, Human Resource Practices and Employee Satisfaction are inextricably linked.

Table 4: HR Practices and Employee Retention

\begin{tabular}{|ll|l|l|}
\hline MEANHP & Pearson Correlation & 1 & $.958^{* *}$ \\
& Sig. (2-tailed) & & .000 \\
& $\mathrm{~N}$ & 330 & 330 \\
\hline MEANER & Pearson Correlation & $.958^{* *}$ & 1 \\
& Sig. (2-tailed) & .000 & \\
$\mathrm{~N}$ & 330 & 330 \\
\hline
\end{tabular}

\section{Multiple Regression Analysis}

The regression analysis is shown in Table 5. Correlation coefficient $R=0.999$ indicates that dependent and independent variables have a positive connection. The $R$ square value of 0.997 demonstrates that the four independent factors influence 99.7 per cent of the variation in the dependent variable. 


\begin{tabular}{|c|c|c|c|c|c|c|c|c|c|}
\hline \multirow[b]{2}{*}{$\begin{array}{l}\text { Mod } \\
\text { el }\end{array}$} & \multirow[b]{2}{*}{$\mathrm{R}$} & \multirow[b]{2}{*}{$\begin{array}{l}R \\
\text { Square }\end{array}$} & \multirow[b]{2}{*}{$\begin{array}{l}\text { Adjusted } \\
\text { R Square }\end{array}$} & \multirow[b]{2}{*}{$\begin{array}{lr}\text { Std. Error } \\
\text { of } & \text { the } \\
\text { Estimate }\end{array}$} & \multicolumn{5}{|c|}{ Change Statistics } \\
\hline & & & & & $\begin{array}{l}\text { R Square } \\
\text { Change }\end{array}$ & F Change & df1 & df2 & $\begin{array}{ll}\text { Sig. } & F \\
\text { Change } & \end{array}$ \\
\hline 1 & $.999^{a}$ & .997 & .997 & .04304 & .997 & 13971.550 & 9 & 320 & .000 \\
\hline
\end{tabular}

a. Predictors: (Constant) Gender, Job Tenure, Organization Position, Age, MEANHP, Education,

b. Dependent Variable: MEANER

\section{Conclusions}

The study examined the effect of HR practices on employee retention in Oman's oil and gas industry. The data was collected through an online survey method by providing a set of questionnaires to the respondent wherein 320 respondents were responded. However, the key findings from the study are as follows-

1. Most of the respondents from the oil and gas industry in Oman positively support the HR practices of the company.

2. Most of the respondents from the oil and gas industry in Oman positively supported the employee retention process of the company.

3. There is a remarkable positive correlation between HR practices and employee retention in the oil and gas industry of Oman according to Pearson Correlations Coefficient and Multiple Regression Analysis.

\section{References}

Bashir, H. A., Alzebdeh, K., \& Al Riyami, A. (2014). Factor analysis of obstacles restraining productivity improvement programs in manufacturing enterprises in Oman. Journal of Industrial Engineering, 2014.

Belwal, S., \& Belwal, R. (2014). Work-life balance, family-friendly policies and quality of work life issues: studying employers' perspectives of working women in Oman. Journal of International Women's Studies, 15(1), 96-117.

Bloom, N., \& Van Reenen, J. (2010). Why do management practices differ across firms and countries?. Journal of economic perspectives, 24(1), 203-24.

Brynjolfsson, E., \& Hitt, L. M. (2000). Beyond computation: Information technology, organizational transformation and business performance. Journal of Economic perspectives, 14(4), 23-48.

Chhabra, B., \& Mohanty, R. P. (2014). Mediating role of organisation commitment in the relationship between job satisfaction and organisational citizenship behaviour: a study of Indian IT professionals. International Journal of Indian Culture and Business Management, 9(4), 449-467.

Cross, R., Laseter, T., Parker, A., \& Velasquez, G. (2004). Assessing and improving communities of practice with organizational network analysis. The Network Roundtable at the University of Virginia.

Damanpour, F., \& Gopalakrishnan, S. (1998). Theories of organizational structure and innovation adoption: the role of environmental change. Journal of Engineering and technology management, 15(1), 1-24. 
Farouk, S., Abu Elanain, H. M., Obeidat, S. M., \& Al-Nahyan, M. (2016). HRM practices and organizational performance in the UAE banking sector: The mediating role of organizational innovation. International Journal of Productivity and Performance Management, 65(6), 773-791.

Harter, J. K., Schmidt, F. L., \& Hayes, T. L. (2002). Business-unit-level relationship between employee satisfaction, employee engagement, and business outcomes: a metaanalysis. Journal of applied psychology, 87(2), 268.

Hendry, C., \& Pettigrew, A. (1986). The practice of strategic human resource management. Personnel review, 15(5), 3-8.

Hislop, D. (2003). The complex relations between communities of practice and the implementation of technological innovations. International Journal of Innovation Management, 7(2), 163-188.

Morrow, P. C., \& McElroy, J. C. (2001). Work commitment-Conceptual and methodological developments for the management of human resources. Human Resource Management Review, 3(11), 177-180.

Moynihan, L. M., Gardner, T. M., Park, H. J., \& Wright, P. M. (2001). HR practices and customer satisfaction: The mediating link of commitment. (CAHRS Working Paper 01-14), Ithaca, NY: Cornell University, School of Industrial and Labor Relations, Center for Advanced Human Resource Studies.

Tan, C. L., \& Nasurdin, A. M. (2010). Knowledge management effectiveness and technological innovation: An empirical study in the Malaysian manufacturing industry. Journal of Mobile Technologies, Knowledge and Society, 25(3), 13-17.

Zikmund, W. G., Babin, B. J., Carr, J. C., \& Griffin, M. (2003). Research methods. Health economics research method, 2. 